\title{
Particle settling and vertical mixing in the Saharan Air Layer as seen from an integrated model, lidar, and in situ perspective
}

\author{
Josef Gasteiger $^{1,2}$, Silke Groß ${ }^{3}$, Daniel Sauer ${ }^{3}$, Moritz Haarig ${ }^{4}$, Albert Ansmann ${ }^{4}$, and Bernadett Weinzierl ${ }^{2}$ \\ ${ }^{1}$ Meteorologisches Institut, Ludwig-Maximilians-Universität, München, Germany \\ ${ }^{2}$ Faculty of Physics, University of Vienna, Vienna, Austria \\ ${ }^{3}$ Institut für Physik der Atmosphäre, Deutsches Zentrum für Luft- und Raumfahrt, Oberpfaffenhofen, Germany \\ ${ }^{4}$ Leibniz Institute for Tropospheric Research, Leipzig, Germany
}

Correspondence to: Josef Gasteiger (josef.gasteiger@univie.ac.at)

Received: 6 June 2016 - Published in Atmos. Chem. Phys. Discuss.: 17 June 2016

Revised: 15 November 2016 - Accepted: 11 December 2016 - Published: 5 January 2017

\begin{abstract}
Long-range transport of aerosol in the Saharan Air Layer (SAL) across the Atlantic plays an important role for weather, climate, and ocean fertilization. However, processes occurring within the SAL and their effects on aerosol properties are still unclear. In this work we study particle settling and vertical mixing within the SAL based on measured and modeled vertical aerosol profiles in the upper $1 \mathrm{~km}$ of the transported SAL. We use ground-based lidar measurements and airborne particle counter measurements over the western Atlantic, collected during the SALTRACE campaign, as well as space-based CALIOP lidar measurements from Africa to the western Atlantic in the summer season. In our model we take account of the optical properties and the Stokes gravitational settling of irregularly shaped Saharan dust particles.

We test two hypotheses about the occurrence of vertical mixing within the SAL over the Atlantic to explain the aerosol profiles observed by the lidars and the particle counter. Our first hypothesis (H1) assumes that no mixing occurs in the SAL leading to a settling-induced separation of particle sizes. The second hypothesis (H2) assumes that vertical mixing occurs in the SAL allowing large super-micron dust particles to stay airborne longer than without mixing.

The uncertainties of the particle linear depolarization ratio $\left(\delta_{1}\right)$ profiles measured by the ground-based lidars are comparable to the modeled differences between $\mathrm{H} 1$ and $\mathrm{H} 2$ and do not allow us to conclude which hypothesis fits better. The SALTRACE in situ data on size-resolved particle number concentrations show a presence of large particles near the SAL top that is inconsistent with H1. The analysis of the CALIOP measurements also reveals that the average $\delta_{1}$ pro-
\end{abstract}

file over the western Atlantic is inconsistent with H1. Furthermore, it was found that the average $\delta_{1}$ profile in the upper $1 \mathrm{~km}$ of the SAL does not change along its transport path over the Atlantic. These findings give evidence that vertical mixing within the SAL is a common phenomenon with significant consequences for the evolution of the size distribution of super-micron dust particles during transport over the Atlantic. Further research is needed to precisely characterize the processes that are relevant for this phenomenon.

\section{Introduction}

The Saharan Air Layer (SAL) carries large amounts of Saharan aerosol particles towards the western Atlantic Ocean and the Americas, in particular during summer (e.g., Prospero and Carlson, 1972; Carlson and Prospero, 1972; Schütz, 1980; Tsamalis et al., 2013). The SAL over the African continent is often a well-mixed convective layer from the hot surface to about 4-6 km a.s.l. (Ben-Ami et al., 2009; Knippertz et al., 2009; Cuesta et al., 2009; Esselborn et al., 2009). As soon as the SAL reaches the Atlantic, it is lifted over a comparatively cold marine boundary layer. As a consequence, the radiative heating at the bottom of the SAL, which is a strong driving force for convection, vanishes. However, vertical mixing within the SAL over the Atlantic might be possible due to other radiative or dynamic effects. Knowledge about those processes is quite limited, but they can be important for the evolution of the particle size distribution during transport. Changes in size distribution can have signifi- 
cant effects for radiative properties and deposition of Saharan aerosols (e.g., Otto et al., 2009; Mahowald et al., 2014).

Size distribution measurements performed at Izaña (Canary Islands) and Puerto Rico (Caribbean) by Maring et al. (2003) revealed that Saharan dust particles with $r>3.6 \mu \mathrm{m}$ are preferentially removed during the transport over the Atlantic. Maring et al. (2003) cannot explain their measurements by assuming that Stokes gravitational settling is the only process occurring during transport over the Atlantic. They have to reduce the Stokes settling velocity by $0.0033 \mathrm{~m} \mathrm{~s}^{-1}$ to match the measurements, which could be an indication for vertical mixing of air during the transport. The lack of significant vertical changes of particle size distributions found by Reid et al. (2003) in the Caribbean also indicates that settling is counteracted by some other processes.

Lidar remote sensing is a powerful tool for localizing and characterizing aerosols, including their size distributions. The particle linear depolarization ratio $\delta_{1}$ (Sassen, 1991), measured by advanced lidar systems, is a particularly useful parameter for characterizing Saharan aerosols. For example, in a case study, Liu et al. (2008) characterize a dust outbreak that was transported from the Sahara over the Atlantic. They use measurements of the CALIOP lidar (Winker et al., 2009), which is operated onboard the CALIPSO satellite and measures $\delta_{1}$ at a wavelength of $532 \mathrm{~nm}$. Liu et al. (2013) investigate Asian dust and its transport over the Pacific using data from the same instrument. The network EARLINET (Pappalardo et al., 2014) provides a comprehensive data set on ground-based lidar measurements throughout Europe, which is useful for studying Saharan aerosols transported to Europe (see e.g., Mattis et al., 2002; Papayannis et al., 2008; Wiegner et al., 2011). During field campaigns like PRIDE (Reid et al., 2003), SAMUM (Heintzenberg, 2009; Ansmann et al., 2011), Fennec (Ryder et al., 2013), and SALTRACE (Weinzierl et al., 2016), Saharan aerosol was measured using a wide set of techniques, including lidar, photometer, and airborne in situ instrumentation. The combination of different measurement techniques enables one to better constrain the properties of the rather complex Saharan aerosol. Polarization-sensitive (near-) backscattering by dusty aerosols is also studied in laboratories (e.g., Sakai et al., 2010; Järvinen et al., 2016).

Yang et al. (2013) investigate Saharan aerosols on their way over the Atlantic based on $\delta_{1}$ data from CALIOP. They use $\delta_{1}$ from volumes that the CALIPSO operational algorithm classified as dust-laden and average $\delta_{1}$ as function of height above sea level, over the summer season 2007. The averaged $\delta_{1}$ profiles show an increasing height dependence with increasing distance from Africa. Over the western Atlantic they find the largest $\delta_{1}$ values at altitudes of about $4-5 \mathrm{~km}$ and a decrease of $\delta_{1}$ with decreasing altitude. Yang et al. (2013) explain the averaged CALIOP $\delta_{1}$ profiles with settling-induced separation of particle shapes using a model that assumes that particles with nearly spherical shape settle faster and have smaller $\delta_{1}$ than particles with stronger deviation from spherical shape.

In our study we investigate the Saharan aerosol transport over the Atlantic by combining advanced modeling efforts with data obtained from ground-based lidar, airborne particle counters, and the CALIOP lidar. We show theoretical profiles for Saharan aerosols considering gravitational settling as a function of particle size and shape. We differentiate between two hypotheses about the occurrence of vertical mixing within the SAL. The lidar-relevant optical properties are simulated based on the particle microphysics explicitly using an optical model. We compare our modeled profiles with the measured data that we evaluate as a function of distance from the SAL top. The ground-based and airborne measurements used in our study were performed during the SALTRACE field campaign (Weinzierl et al., 2016) in the summer of 2013 in the vicinity of Barbados (Caribbean). From CALIOP, we use nighttime profile data covering 15 summer months and the Saharan aerosol transport region from Africa to the Caribbean.

After describing our modeling approach (Sect. 2) we investigate modeled lidar profiles after 5 days of transport without vertical mixing (Sect. 3.1), which is a typical transport time of Saharan aerosol to the Caribbean. The sensitivity of $\delta_{1}$ profiles to particle shape (Sect. 3.2) and to the shape dependence of the settling velocity (Sect. 3.3) is subsequently investigated. In Sect. 3.4 we model the effect of daytime convective vertical mixing occurring in the SAL during transport. Subsequently, the modeled profiles are compared in a case study to lidar and in situ profiles measured in Barbados during SALTRACE (Sect. 4) to test our two hypotheses about vertical mixing in the SAL over the Atlantic. In Sect. 5 we continue testing these hypotheses by using averaged CALIOP profiles before we give concluding remarks in Sect. 6 .

\section{Model description}

Our model describes Saharan aerosols in the SAL. We consider six irregular dust particle shapes, as introduced by Gasteiger et al. (2011), with shapes A-C being deformed prolate spheroids with varying aspect ratio, shape $\mathrm{D}$ an aggregate, and shapes E-F edged particles with varying aspect ratio (these shapes are depicted further down in Fig. 5 together with their aspect ratios). Though this low number of model shapes is not sufficient to represent all aspects of Saharan dust in full detail, model ensembles composed of these dust shapes and small water-soluble particles can be used to approximate optical properties of Saharan aerosols (Gasteiger et al., 2011). We assume the particles to be randomly oriented. We furthermore assume that the SAL is initially well-mixed and that gravitational settling of the aerosol particles is the only process when no vertical mixing occurs. 
We also consider the case of a diurnal cycle of the convective vertical mixing activity.

\subsection{Stokes settling}

The settling velocity $v$ of a particle relative to the ambient air is determined by the balance between gravitational force $F_{\mathrm{g}}$ and drag force $F_{\mathrm{d}}$ if other forces can be neglected. The gravitation force is given by

$F_{\mathrm{g}}=\frac{4}{3} \pi r_{\mathrm{v}}^{3} \rho g$,

with the volume-equivalent radius $r_{\mathrm{V}}$ of the particle, the gravitational acceleration $g=9.81 \mathrm{~m} \mathrm{~s}^{-2}$, and the particle density $\rho$ that we assume to be $2.6 \times 10^{3} \mathrm{~kg} \mathrm{~m}^{-3}$ for mineral dust particles (Hess et al., 1998). The drag force of a settling aerosol particle in the size range of $r \approx 0.5 \mu \mathrm{m}$ to $r \approx 10 \mu \mathrm{m}$ (being in the Stokes drag regime) can be approximated by

$F_{\mathrm{d}}=6 \pi \eta r_{\mathrm{c}} v$,

with the dynamic viscosity of air $\eta=17 \mu \mathrm{Pa}$ s (approximate value for a temperature of $0^{\circ} \mathrm{C}$ and tropospheric pressures) and the cross-section-equivalent radius $r_{\mathrm{c}}$ of the particle. We use $r_{\mathrm{c}}$ instead of $r_{\mathrm{v}}$ in this equation because the drag force is related more to the cross section of the particle than to its volume.

We note that using $r_{\mathrm{c}}$ in Eq. (2) is an approximation because determining the exact Stokes drag force of an irregularly shaped particle is a more complex issue; see e.g., Loth (2008). The drag force of a particle larger than $r \approx 10 \mu \mathrm{m}$ is stronger than calculated with Eq. (2). For example, in the case of spherical particles, $F_{\mathrm{d}}$ is increased by about $5 \%$ for $r=20 \mu \mathrm{m}$ and about $15 \%$ for $r=30 \mu \mathrm{m}$ compared to Stokes law (Hinds, 1999). In addition, because of the flow around the settling particle, coarse nonspherical particles can become horizontally aligned. Using the formula about the probability distributions of orientation angles of prolate spheroids compiled by Ulanowski et al. (2007), we estimate that settling-induced alignment occurs for dust particles with $r>5 \mu \mathrm{m}$. In the Stokes regime, for typical dust aspect ratios of 1.6-1.8, $F_{\mathrm{d}}$ of a spheroid in horizontal orientation is on average about $5 \%$ stronger than the average $F_{\mathrm{d}}$ of the same particle in random orientation (Clift et al., 1978). In the following, we stick to Eq. (2) for the calculation of $F_{\mathrm{d}}$ because these deviations have only a negligible effect on the profiles presented below.

Setting $F_{\mathrm{g}}=F_{\mathrm{d}}$ and using the conversion factor $\xi_{\mathrm{vc}}=$ $r_{\mathrm{v}} / r_{\mathrm{c}}$ (Gasteiger et al., 2011) results in a settling velocity of the particle relative to the ambient air of

$v=\frac{2 g \rho}{9 \eta} \cdot r_{\mathrm{c}}^{2} \cdot \xi_{\mathrm{vc}}^{3}$.

$\xi_{\mathrm{vc}}$ of our six irregular model shapes is 0.955 (shape A), 0.932 (B), 0.911 (C), 0.871 (D), 0.925 (E), and 0.866 (F).

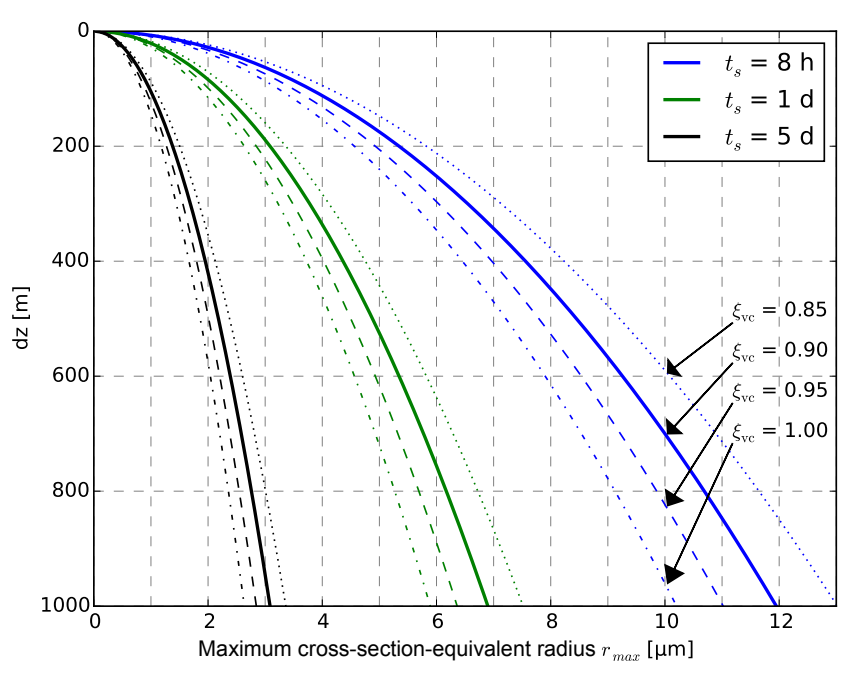

Figure 1. Maximum cross-section-equivalent radius $r_{\max }$ of dust particles as a function of distance $\mathrm{d} z$ from the SAL top after different settling time periods $t_{\mathrm{S}}$ assuming different shape-dependent conversion factors $\xi_{\mathrm{vc}} \cdot \xi_{\mathrm{vc}}=1$ corresponds to spherical particles.

Note that the dynamic shape factor $\chi$ (Hinds, 1999) is $\chi=\xi_{\mathrm{vc}}^{-1}$ if $r_{\mathrm{v}}$ is assumed and $\chi=\xi_{\mathrm{vc}}^{-3}$ if $r_{\mathrm{c}}$ is assumed for the radius. Henceforth, unless otherwise stated, we use the cross-section-equivalent radius $r=r_{\mathrm{c}}$ for describing particle size.

As a result of gravitational settling during a time period $t_{\mathrm{s}}$ without vertical mixing, the maximum particle radius $r_{\max }$ at a distance $\mathrm{d} z$ from the upper boundary of the SAL is given by

$r_{\max }=\sqrt{\frac{9 \eta \mathrm{d} z}{2 g \rho \xi_{\mathrm{vc}}^{3} t_{\mathrm{s}}}}$.

Figure 1 illustrates $r_{\max }$ as function of $\mathrm{d} z$ for different settling time periods $t_{\mathrm{s}}$. The solid lines show $r_{\max }$ for a conversion factor $\xi_{\mathrm{vc}}=0.9$, which is in the range of our dust model shapes. The vertical axis was chosen such that the top of the SAL $(\mathrm{d} z=0 \mathrm{~m})$ is at the top of the figure. For example, at $t_{\mathrm{S}}=5 \mathrm{~d}$, no particles with radii $r>2 \mu \mathrm{m}$ and $\xi_{\mathrm{vc}}=0.9$ exist in the upper $400 \mathrm{~m}$ of the SAL.

\subsection{Hypotheses about occurrence of vertical mixing}

In our first hypothesis (H1) we assume that no vertical mixing of air occurs in the SAL over the Atlantic. By contrast, in our second hypothesis $(\mathrm{H} 2)$ we assume a diurnal cycle of the convection activity. The idea behind $\mathrm{H} 2$ is that the SAL is heated by absorption of sunlight by the aerosol particles, triggering convective vertical mixing during the day. In nature the physics behind vertical mixing of SAL air might differ from what we assume in our idealized $\mathrm{H} 2$ model (see discussion). The possibility of vertical mixing in the SAL is consistent with the almost height-independent potential temperature profiles observed within the SAL (see e.g., Carlson 


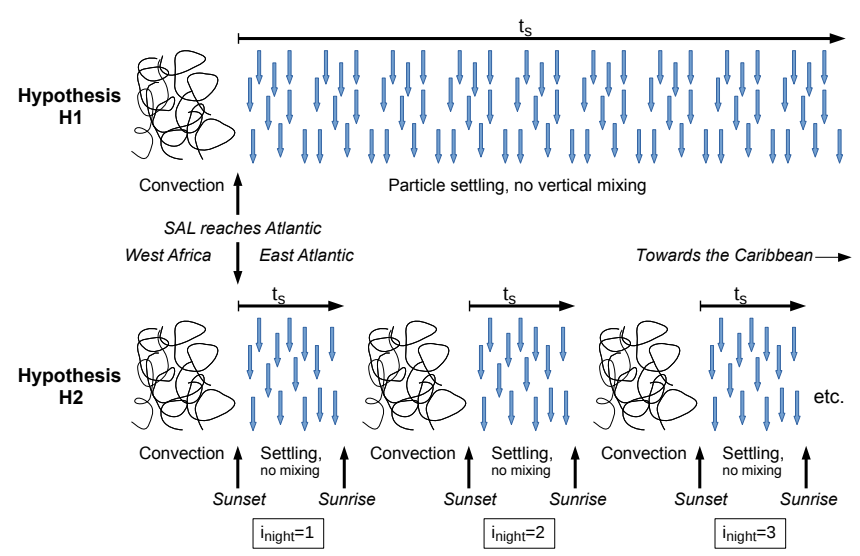

Figure 2. Schematic view of timing in hypotheses about the occurrence of settling and convective vertical mixing within the SAL.

and Prospero (1972) or further down in Fig. 8). We emphasize that the convection activity studied here is not connected to the convection occurring in the marine boundary layer (which sometimes affects the lower parts of the SAL).

Both hypotheses are illustrated in Fig. 2. We model the transport for one vertical column, ignoring possible wind shear or convergence. For simplicity, we assume that the SAL reaches the Atlantic at first sunset. Furthermore, we assume convective vertical mixing to always be perfect, though in reality convection may be weak and the vertical mixing imperfect. In the case of $\mathrm{H} 2$, the initial aerosol size distribution at $t_{\mathrm{s}}=0$ varies from night to night because a certain fraction of particles is removed by settling during the convection-free time each night before convective vertical mixing starts again with sunrise. The fraction $f$ of particles that remains in the SAL after one night is calculated for $z_{\text {settled }}\left(r, \xi_{\mathrm{vc}}\right)<H_{\mathrm{SAL}}$ using

$f\left(r, \xi_{\mathrm{vc}}\right)=\frac{\exp \left(\frac{H_{\mathrm{SAL}}-z_{\text {settled }}\left(r, \xi_{\mathrm{vc}}\right)}{H_{\mathrm{scale}}}\right)-1}{\exp \left(\frac{H_{\mathrm{SAL}}}{H_{\mathrm{scale}}}\right)-1}$,

where $z_{\text {settled }}\left(r, \xi_{\mathrm{vc}}\right)$ is the distance the particles have settled during the night. No particles with $z_{\text {settled }}\left(r, \xi_{\mathrm{vc}}\right)>H_{\mathrm{SAL}}$ are in the SAL after the first night. $z_{\text {settled }}$ is calculated using $v$ from Eq. (3) and a night duration of $11 \mathrm{~h}$, which is a typical value for the northern tropical Atlantic during summertime. $H_{\mathrm{SAL}}$ is the depth of the SAL within which convective vertical mixing occurs each day. We use $H_{\mathrm{SAL}}=3 \mathrm{~km}$. In Eq. (5) we assume that the particles are well-mixed within the SAL at sunset. Those particles that settle during the night below the lower boundary of the SAL (determined by $H_{\mathrm{SAL}}$ ) are considered as removed from the SAL at sunrise when mixing starts again. Equation (5) considers the exponential decrease of the air density and thus the amount of aerosol (in the case of well-mixed layers) with height. We assume a scale height $H_{\text {scale }}=10 \mathrm{~km}$, which implies an exponential decrease by a factor of $e$ from the ground to $10 \mathrm{~km}$ height. This value of

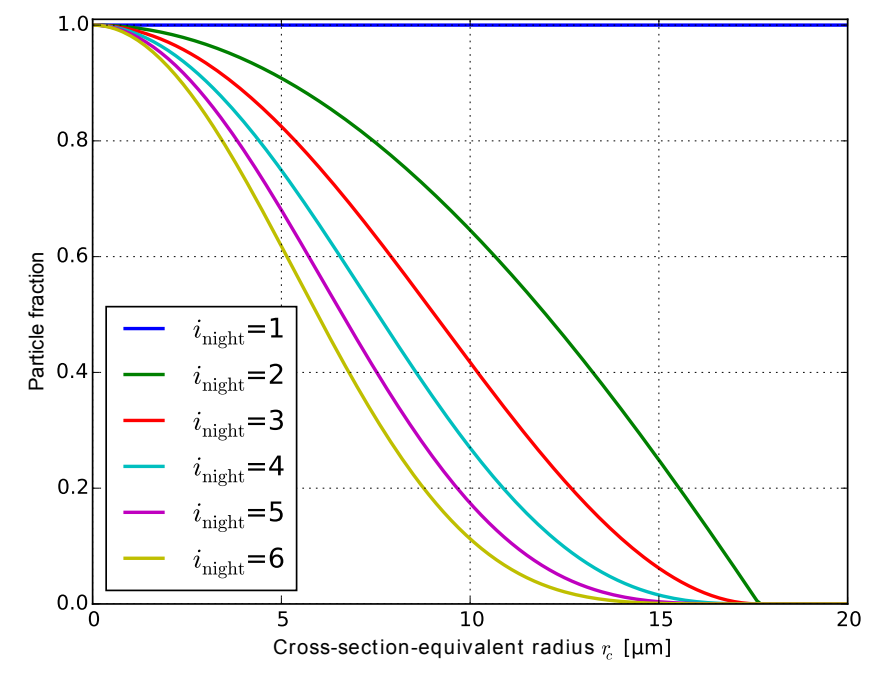

Figure 3. Fraction of particles (relative to initial size distribution) existing in SAL at the beginning of each night $\left(t_{\mathrm{S}}=0\right)$ in the case of $\mathrm{H} 2$ and $\xi_{\mathrm{vc}}=0.90$.

$H_{\text {scale }}$ was estimated from the tropical standard atmosphere provided by Anderson et al. (1986).

Figure 3 shows the fraction of the particles present in the SAL at the beginning of each night for $\mathrm{H} 2$ (counted by $i_{\text {night }}$ as illustrated in Fig. 2). This fraction is calculated from Eq. (5) using

$f\left(r, \xi_{\mathrm{vc}}\right)^{\left(i_{\text {night }}-1\right)}$

and is multiplied with the initial aerosol size distribution, which is described below, to get the size distribution at the beginning of each night.

Henceforward in this paper, we denote the hypotheses and points of time using the following notation: for the first hypothesis we write $\left[\mathrm{H} 1, t_{\mathrm{s}}\right]$ and for the second hypothesis we write $\left[\mathrm{H} 2, i_{\text {night }}, t_{\mathrm{s}}\right]$.

\subsection{Aerosol mixtures and optical modeling}

We simulate the optical properties of Saharan aerosols based on their microphysical properties (size, shape, refractive index) as described by Gasteiger et al. (2011) and use the reference ensemble described in that contribution as the initial aerosol ensemble at $[\mathrm{H} 1,0 \mathrm{~h}]$ and $[\mathrm{H} 2,1,0 \mathrm{~h}]$. The lidarrelated optical properties of this ensemble are consistent with measurements of Saharan aerosols over Africa (Gasteiger et al., 2011). The aerosol ensembles consist of four lognormal size modes with one mode of small water-soluble (WASO) particles and three modes of mineral dust particles, as defined for the desert mixture in OPAC (Koepke et al., 2015). For WASO particles, spherical shape, a relative humidity of $50 \%$, and a density of $\rho=1.42 \times 10^{3} \mathrm{~kg} \mathrm{~m}^{-3}$ is assumed. Mixing of mineral dust with WASO particles is consistent with results presented by Kaaden et al. (2009), who found that Saharan aerosol particles in the smaller size 
ranges $(r<0.1-0.25 \mu \mathrm{m})$ consist mainly of ammonium sulfate. Volatile ammonium sulfate particles were also identified in airborne in situ measurements during SAMUM (Weinzierl et al., 2009) and SALTRACE (Weinzierl et al., 2016).

The mineral dust particles of the reference ensemble are an equiprobable mix of shapes B, C, D, and F (Gasteiger et al., 2011). The optical properties of dust particles with $2 \pi r_{\mathrm{v}} / \lambda \leq 25$ were calculated with the discrete dipole approximation code ADDA (Yurkin and Hoekstra, 2011) and for larger particles it was assumed that the lidar ratio $S$ and the linear depolarization ratio $\delta_{1}$ are size-independent, i.e., $S$ and $\delta_{1}$ calculated for $2 \pi r_{\mathrm{v}} / \lambda=25$ were also applied for larger particles.

It has been shown for Saharan aerosols that the refractive index varies from dust particle to dust particle (e.g., Kandler et al., 2011), and that this variability can have significant effects on lidar-relevant optical properties (Gasteiger et al., 2011). In our model, we consider the refractive index variability using the following approximating approach: the imaginary part of the dust refractive index, which is relevant for absorption, is distributed such that $50 \%$ of the dust particles are non-absorbing while the other $50 \%$ have an imaginary part that is doubled compared to the value provided by OPAC, leading to good agreement with SAMUM lidar measurements (Gasteiger et al., 2011).

We apply a maximum cutoff radius $r_{\max }$ that is varied as a function of distance $\mathrm{d} z$ from the SAL top as given by Eq. (4). The maximum $r_{\max }$ is $40 \mu \mathrm{m}$ (at $\mathrm{d} z \leq 1 \mathrm{~km}$ only relevant for $t_{\mathrm{s}}<1 \mathrm{~h}$ ). In the case of a diurnal cycle of convective vertical mixing (H2), we additionally consider the partial removal of particles due to settling each night, as described above (Eq. 6, Fig. 3). The evolution of the mineral dust size distribution for $\mathrm{H} 2$ (each night at $t_{\mathrm{s}}=0$ ) is illustrated in the Supplement $\mathrm{S} 1$.

We simulate vertical profiles of the extinction coefficient $\alpha$, the backscatter coefficient $\beta$, the lidar ratio

$S=\frac{\alpha}{\beta}=\frac{4 \pi}{\omega_{0} F_{11}\left(180^{\circ}\right)}$,

and the linear depolarization ratio

$\delta_{1}=\frac{1-F_{22}\left(180^{\circ}\right) / F_{11}\left(180^{\circ}\right)}{1+F_{22}\left(180^{\circ}\right) / F_{11}\left(180^{\circ}\right)}$.

Here, $\omega_{0}$ is the single scattering albedo of the aerosol particles and $F_{11}\left(180^{\circ}\right)$ and $F_{22}\left(180^{\circ}\right)$ are elements of their scattering matrix at backward direction. We consider the height dependence of the particle concentration of the initially wellmixed layer by multiplying all modeled $\alpha$ and $\beta$ profiles with $\exp \left(\mathrm{d} z / H_{\text {scale }}\right)$. In this paper, $\alpha, \beta, S$, and $\delta_{1}$ are always aerosol particle properties, i.e., without gas contributions.

\section{Modeled lidar profiles}

In this section we first present modeling results for our first hypothesis (H1) with a settling duration of 5 days, which is the typical time span for transport of aerosol in the SAL from the African coast to Barbados (e.g., Schütz, 1980). H1 is selected here because the effects are stronger than in the case of $\mathrm{H} 2$. We investigate the sensitivity of the $\delta_{1}$ profile to the particle shape and the shape dependence of the settling velocity $v$. Finally in the last part of this section, we investigate the effect of the diurnal convective vertical mixing cycle $(\mathrm{H} 2)$ on the $\delta_{1}$ profile.

\subsection{Effect of particle settling (H1)}

Vertical profiles of lidar-relevant optical properties of the aerosol in the upper $1 \mathrm{~km}$ of the SAL, modeled according to $\mathrm{H} 1$ after 5 days without vertical mixing of air $([\mathrm{H} 1,5 \mathrm{~d}])$ are shown in Fig. 4. The solid lines show results for the reference ensemble at three different lidar wavelengths (indicated by color). To illustrate the effect of the WASO particles, we also consider a case in which we removed all WASO particles (dashed lines of same colors).

The lidar ratio $S$ increases towards the top of the SAL (Fig. 4a). $S$ at $\lambda=532$ and $1064 \mathrm{~nm}$ has peaks of about 75 $80 \mathrm{sr}$ in the upper $70 \mathrm{~m}$ of the SAL, decreasing again in the last few meters below the SAL top. Removing the WASO particles from the ensemble has a significant effect on $S$ only near the top of the SAL (compare dashed with solid line).

We find a decrease of the linear depolarization ratio $\delta_{1}$ with decreasing distance $\mathrm{d} z$ from the SAL top (Fig. $4 \mathrm{~b}$ ). The absolute decrease of $\delta_{1}$ depends on wavelength; for example, from $\mathrm{d} z=1000 \mathrm{~m}$ to $\mathrm{d} z=100 \mathrm{~m} \delta_{1}$ decreases by 0.065 , 0.074 , and 0.121 at $\lambda=355,532$, and $1064 \mathrm{~nm}$, respectively. Removing WASO particles strongly increases $\delta_{1}$ at all heights, in particular at short wavelengths (compare blue lines for $\lambda=355 \mathrm{~nm}$ ), illustrating their importance in modeling $\delta_{1}$ of Saharan aerosols. The decrease of $\delta_{1}$ is shifted towards smaller $\mathrm{d} z$ if WASO is neglected but the general shape of the $\delta_{1}$ profiles does not change.

The backscatter coefficient $\beta$, normalized by $\beta$ at $\lambda=355 \mathrm{~nm}$ and $\mathrm{d} z=1000 \mathrm{~m}$, is shown in Fig. 4c. It decreases with decreasing $\mathrm{d} z$, e.g., at $\mathrm{d} z=100 \mathrm{~m}$ and the three lidar wavelengths. $\beta$ of the reference ensemble is reduced by 41,49 , and $63 \%$, respectively, compared to $\beta$ at $\mathrm{d} z=1000 \mathrm{~m}$.

The extinction coefficient $\alpha$ (Fig. 4d) also decreases towards the SAL top; the relative decrease, however, is smaller than for $\beta$, e.g., for the reference ensemble we find values of 36,40 , and $50 \%$ for the height levels mentioned above. WASO particles influence the wavelength dependence of $\beta$ and $\alpha$ at any $\mathrm{d} z$.

In the following we focus on $\delta_{1}$ at $\lambda=532 \mathrm{~nm}$ because $\delta_{1}$ is the intensive aerosol property, i.e., not depending on the amount of particles, which can be measured with high vertical resolution (compared to $S$ from Raman lidar), and many depolarization lidar systems operate at this wavelength. 

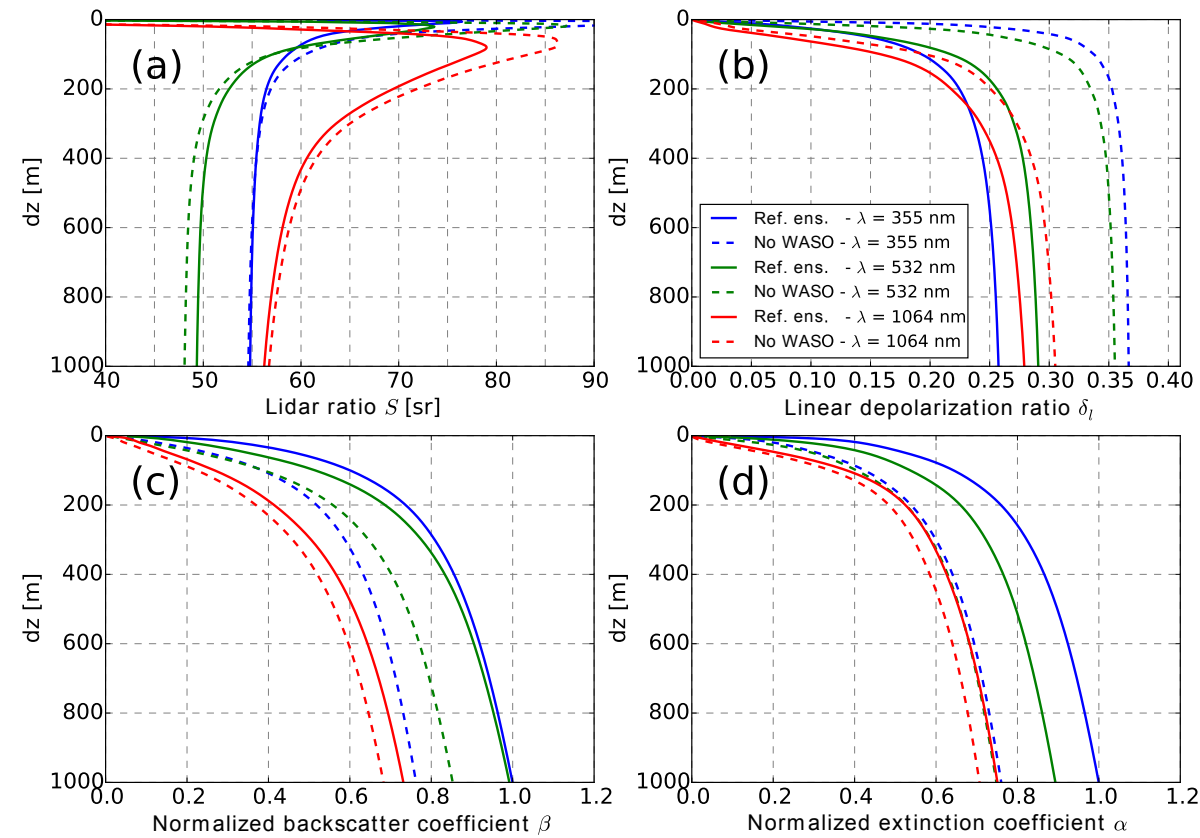

Figure 4. Optical aerosol properties of the upper $1 \mathrm{~km}$ of the SAL for $[\mathrm{H} 1,5 \mathrm{~d}]$ assuming the reference ensemble (solid lines) at three lidar wavelengths (indicated by color). $\beta$ and $\alpha$ are normalized to the value of the reference ensemble at $\lambda=355 \mathrm{~nm}$ and $\mathrm{d} z=1000 \mathrm{~m}$. The dashed lines present profiles when WASO particles are removed from the reference ensemble.

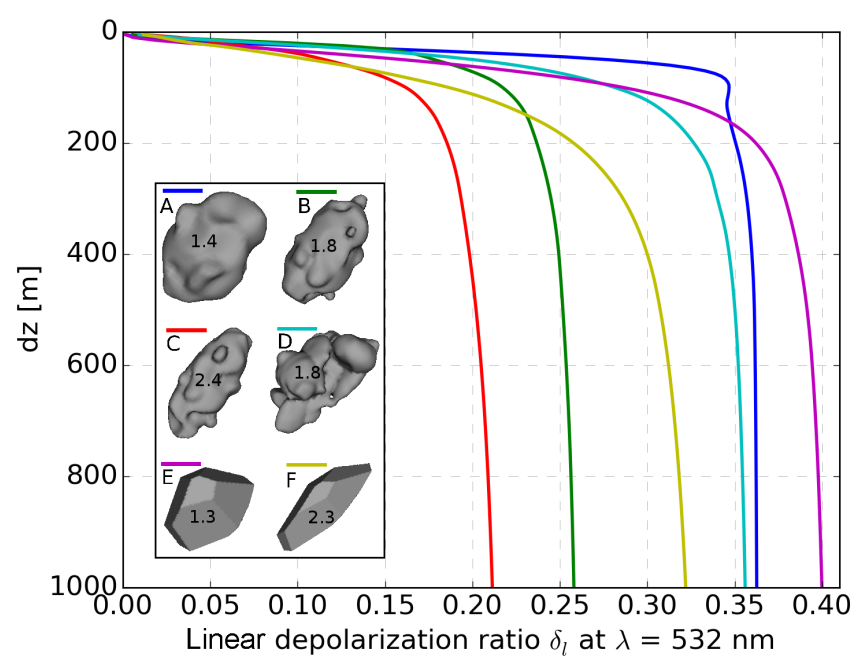

Figure 5. Linear depolarization ratio profiles at $\lambda=532 \mathrm{~nm}$ in the upper $1 \mathrm{~km}$ of the SAL for [H1, $5 \mathrm{~d}]$. The reference ensemble is applied (as in Fig. 4), but only a single dust particle shape is assumed in each profile as indicated in the legend. The approximate aspect ratio is written on each particle.

\subsection{Sensitivity of $\delta_{1}$ profiles to particle shape}

The shape mixture in our reference ensemble may not be fully representative for desert aerosol. Therefore, it is worthwhile to estimate the sensitivity of the lidar profiles to particle shape. Figure 5 shows $\delta_{1}$ profiles at $\lambda=532 \mathrm{~nm}$ for [H1,
$5 \mathrm{~d}$ ] where all dust particles of the reference ensemble were replaced by particles of only a single shape, as indicated in the legend together with their approximate aspect ratios. The other microphysical properties of the dust particles and the properties of the spherical WASO particles were left unchanged. For each profile, the shape-specific $\xi_{\mathrm{vc}}$, as given above, is considered in the calculations.

The absolute value of $\delta_{1}$ at $\lambda=532 \mathrm{~nm}$ depends on particle shape, with a variation range from about 0.2 to 0.4 at $\mathrm{d} z=1000 \mathrm{~m} . \delta_{1}$ of elongated shapes $(\mathrm{C}, \mathrm{F})$ tends to be smaller than $\delta_{1}$ of the more compact counterparts (A, E), illustrating that there is no direct correlation between large aspect ratios and large $\delta_{1}$ (in contrast to what is often assumed in the literature, e.g., Yang et al., 2013). $\delta_{1}$ decreases with decreasing $\mathrm{d} z$ for all considered shapes and the decrease is not strongly sensitive to the selection of the particle shape. However, the decrease of $\delta_{1}$ in the case of shapes D-F (aggregate particles, edged particles) tends to be shifted to larger $\mathrm{d} z$ compared to $\delta_{1}$ in the case of shapes A-C (deformed spheroids). The sensitivity of $\delta_{1}$ profiles to realistic changes of the refractive index and the size distribution was found to be lower (not shown) than the sensitivity to the particle shape (Fig. 5).

\subsection{Sensitivity of $\delta_{1}$ profiles to shape dependence of settling velocity}

Yang et al. (2013) suggest a model for settling-induced separation of particle shapes to explain the observed height dependence of $\delta_{1}$. They consider the shape dependence of the 


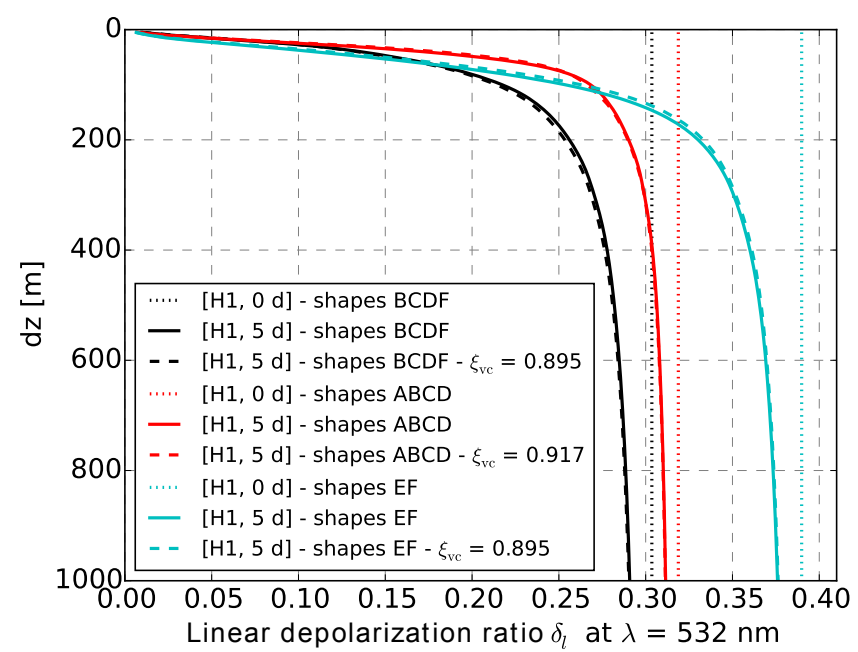

Figure 6. Analogous to Fig. 5, but assuming mixtures of different shapes of mineral dust particles as indicated in the legend (shapes $\mathrm{BCDF}=$ reference ensemble). The solid lines show profiles for $[\mathrm{H} 1$, $5 \mathrm{~d}]$. The dashed lines show the same profiles when no shape dependence of the settling velocity is assumed ( $\xi_{\mathrm{vc}}$ of all shapes is set to the average value, which is given in the legend). The dotted lines show the modeled profile at the beginning of the settling.

settling velocity $v$ but not the size dependence of $v$. Here, we investigate how sensitive $\delta_{1}$ profiles are to the shape dependence of $v$ compared to the size dependence of $v$. For this purpose, Fig. 6 shows $\delta_{1}$ profiles at $\lambda=532 \mathrm{~nm}$ for [H1, $5 \mathrm{~d}$ ] and for three different shape mixtures, which are indicated by color (mixture BCDF corresponds to the reference ensemble used in most other parts of this paper). The solid lines illustrate results when shape-dependent $\xi_{\mathrm{vc}}$ are considered. By contrast, results shown as dashed lines assumed the average $\xi_{\mathrm{vc}}$ value (as displayed in the legend) for the settling of all dust shapes, implying that the shape dependence of $v$ is switched off. For comparison, the initial $\delta_{1}$ profiles at $[\mathrm{H} 1,0 \mathrm{~d}]$ are also shown as dotted lines. Thus, the differences between the dotted and the solid lines show the total settling effect after 5 days without vertical mixing and the differences between solid and dashed lines show the effect of the shape dependence of the settling velocity. The latter effect is much smaller than the total settling effect, independent of the assumed shape mixture. This allows us to conclude that the settling-induced separation of particle shapes is only of minor importance for $\delta_{1}$ compared to the settling-induced separation of particle sizes. These results are consistent with results presented by Ginoux (2003).

\subsection{Effect of diurnal convection cycle (H2)}

Figure 7 shows $\delta_{1}$ profiles for both hypotheses, different time periods without mixing $\left(t_{\mathrm{s}}\right)$, and different number of nights $\left(i_{\text {night }}\right)$, assuming our reference ensemble as the initial ensemble. The effect of settling on the $\delta_{1}$ profile increases with

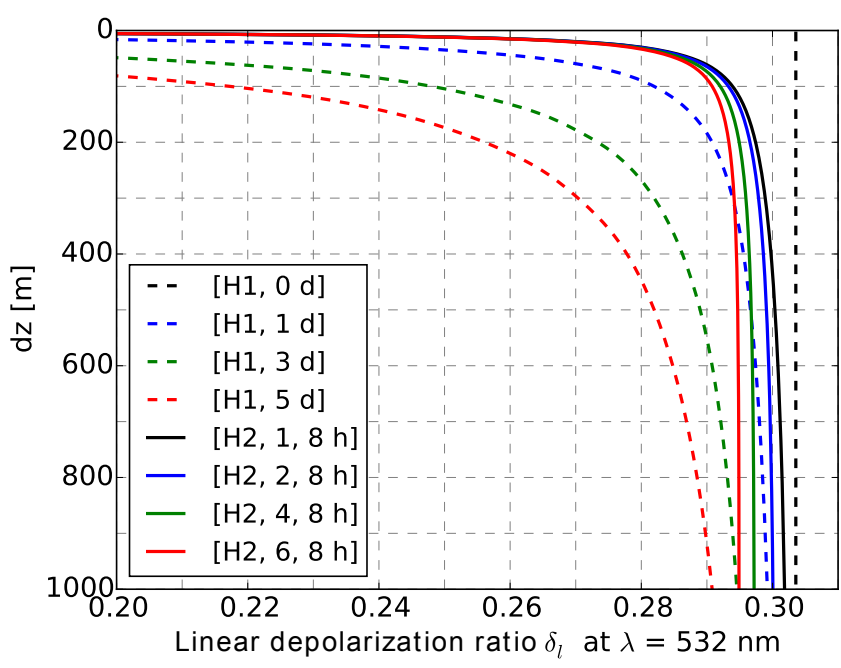

Figure 7. Linear depolarization ratio $\delta_{1}$ profiles at $\lambda=532 \mathrm{~nm}$ in the upper $1 \mathrm{~km}$ of the SAL for both hypotheses after different transport time periods.

increasing $t_{\mathrm{s}}$, in particular in the upper few hundred meters of the SAL (H1, compare dashed lines). In case daytime vertical mixing occurs $(\mathrm{H} 2)$, the nighttime $\delta_{1}$ profile (shown here for $8 \mathrm{~h}$ after sunset) changes only slightly from day to day, with the maximum changes occurring at lower altitudes (compare solid lines). For example, $\delta_{1}$ is reduced by about 0.007 at $\mathrm{d} z=1000 \mathrm{~m}$ from the first night $\left(i_{\text {night }}=1\right)$ to the sixth night $\left(i_{\text {night }}=6\right)$. The differences between the $\delta_{1}$ profiles for $\mathrm{H} 1$ and those for $\mathrm{H} 2$ increase with time (lines of same color correspond to approximately the same transport time), illustrating the sensitivity of the $\delta_{1}$ profiles to the occurrence of vertical mixing.

\section{Comparison with SALTRACE data}

We now discuss our modeling results based on a comparison with aerosol data measured during the SALTRACE field campaign (Weinzierl et al., 2016) in the upper $1 \mathrm{~km}$ of the SAL and test our two hypotheses using this data set.

\subsection{Lidar measurements}

Lidar measurements and radiosonde launches were performed on the grounds of the Caribbean Institute for Meteorology and Hydrology in Bridgetown, Barbados $\left(13.15^{\circ} \mathrm{N}\right.$, $59.62^{\circ} \mathrm{W}, 110 \mathrm{~m}$ a.s.1.). Data from the lidar system POLIS of the Ludwig-Maximilians-Universität (Munich) (Groß et al., 2015; Freudenthaler et al., 2016), data from the lidar system BERTHA of the TROPOS (Leipzig) (Althausen et al., 2000; Haarig et al., 2016), and radiosonde data measured by TROPOS are available. POLIS and BERTHA are Raman lidar systems, thus requiring strong temporal and vertical smoothing for the determination of profiles of lidar ratio 


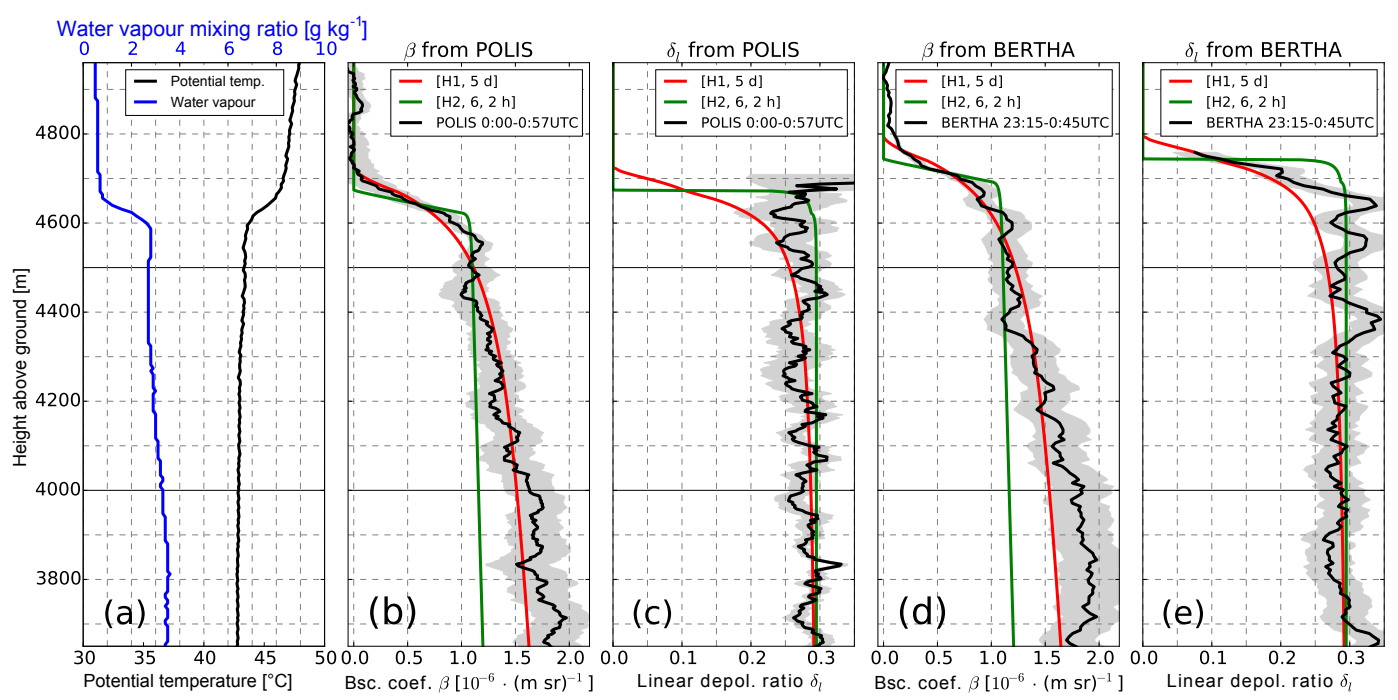

Figure 8. Vertical profiles over Barbados around 00:00 UTC on 11 July 2013. (a) Profile of potential temperature (black) and water vapor mixing ratio (blue) from a radiosonde launched at 23:39 UTC on 10 July 2013. (b) Particle backscatter coefficient $\beta$ and (c) particle linear depolarization ratio $\delta_{1}$ at $\lambda=532 \mathrm{~nm}$ from POLIS measured between 00:00 and 00:57 UTC on 11 July 2013. (d) Particle backscatter coefficient $\beta$ and (e) particle linear depolarization ratio $\delta_{1}$ at $\lambda=532 \mathrm{~nm}$ from BERTHA measured between 23:15 UTC on 10 July 2013 and 00:45 UTC on 11 July 2013. The shaded areas indicate the sum of the systematical and statistical uncertainties of the measured profiles. Corresponding modeled lidar profiles for H1 (red) and H2 (green) are shown. The SAL top heights of the modeled profiles were fitted to the measured $\beta$ profiles (heights given in main text). A flat smoothing window of about $50 \mathrm{~m}$ is used for the measured and modeled lidar profiles.

$S$ and extinction coefficient $\alpha$. A vertical smoothing length of at least $500 \mathrm{~m}$ is required for those properties, but even with this smoothing length the signal-to-noise ratio of the Raman measurements is still too low for a meaningful comparison with our modeled vertical profiles. Therefore, we restrict our comparison to the linear depolarization ratio $\delta_{1}$ and the backscatter coefficient $\beta$, for which a significantly shorter smoothing length is sufficient. Furthermore, we consider only $\lambda=532 \mathrm{~nm}$ for our comparison.

The lidar measurements presented in this section were performed around 00:00 UTC at night from 10 to 11 July 2013. Sunset was at 22:28 UTC. Back trajectory analysis for this air mass using HYSPLIT (Stein et al., 2015) suggests that it had left the African continent about 5 days before the measurements (see the Supplement S2). To test our hypotheses about the occurrence of vertical mixing, we assume for this comparison $t_{\mathrm{s}}=5 \mathrm{~d}$ in the case of $\mathrm{H} 1$, and $t_{\mathrm{S}}=2 \mathrm{~h}$ and $i_{\text {night }}=6$ in the case of $\mathrm{H} 2$.

Figure 8a shows radiosonde data of water vapor mixing ratio (blue) and potential temperature (black). The potential temperature is nearly constant within the SAL, which extends up to about $4600 \mathrm{~m}$ above ground. This potential temperature profile indicates that vertical mixing might have occurred during the transport of this air mass over the Atlantic. The relative humidity at $4500-4600 \mathrm{~m}$ is about 50 to $54 \%$. The vertical structure of the water vapor mixing ratio and the potential temperature might be regarded as typical for the SAL (Carlson and Prospero, 1972).
Figure $8 \mathrm{~b}$ and $\mathrm{c}$ show $\beta$ and $\delta_{1}$ profiles measured by POLIS (black line), temporally averaged over almost $1 \mathrm{~h}$, including the sum of the systematic and statistical uncertainties. Figure $8 \mathrm{~d}$ and e show $\beta$ and $\delta_{1}$ profiles measured by BERTHA (black line), temporally averaged over $1.5 \mathrm{~h}$, including the estimated uncertainties. For comparison, profiles modeled for our hypotheses H1 (red) and H2 (green) are also plotted in Fig. 8. The SAL top heights of the modeled profiles were fitted to the measured $\beta$ profiles. The fitted SAL top height is $4700 \mathrm{~m}$ for $\mathrm{H} 1$ and $4650 \mathrm{~m}$ for $\mathrm{H} 2$ in the case of POLIS, whereas it is $4770 \mathrm{~m}$ for $\mathrm{H} 1$ and $4720 \mathrm{~m}$ for $\mathrm{H} 2$ in the case of BERTHA. Measured and modeled lidar profiles shown in Fig. 8 were vertically smoothed with a flat window of about $50 \mathrm{~m}$ length.

The measured $\beta$ profiles are better fitted by the profile modeled for $\mathrm{H} 1$ than by the profile modeled for $\mathrm{H} 2$ (Fig. $8 \mathrm{~b}$ and d). The modeled $\delta_{1}$ for $\mathrm{H} 1$ and $\mathrm{H} 2$ is generally close to the measured $\delta_{1}$ in the lower part of the SAL (Fig. 8c and e). At the top of the SAL, where the measurement uncertainties are considerable, the measured $\delta_{1}$ profiles deviate from each other and no conclusion can be drawn on whether $\mathrm{H} 1$ or $\mathrm{H} 2$ better explains the $\delta_{1}$ profiles. At other days during SALTRACE, the lidar profiles and their uncertainties exhibit similar characteristics in the SAL (not shown). Our comparisons indicate that further reductions of uncertainties are desirable to identify transport effects within the SAL by means of lidar data. The investigation of profiles at other wavelengths, e.g., $\delta_{1}$ at $\lambda=1064 \mathrm{~nm}$ (Haarig et al., 2016), might also bring further insights. 

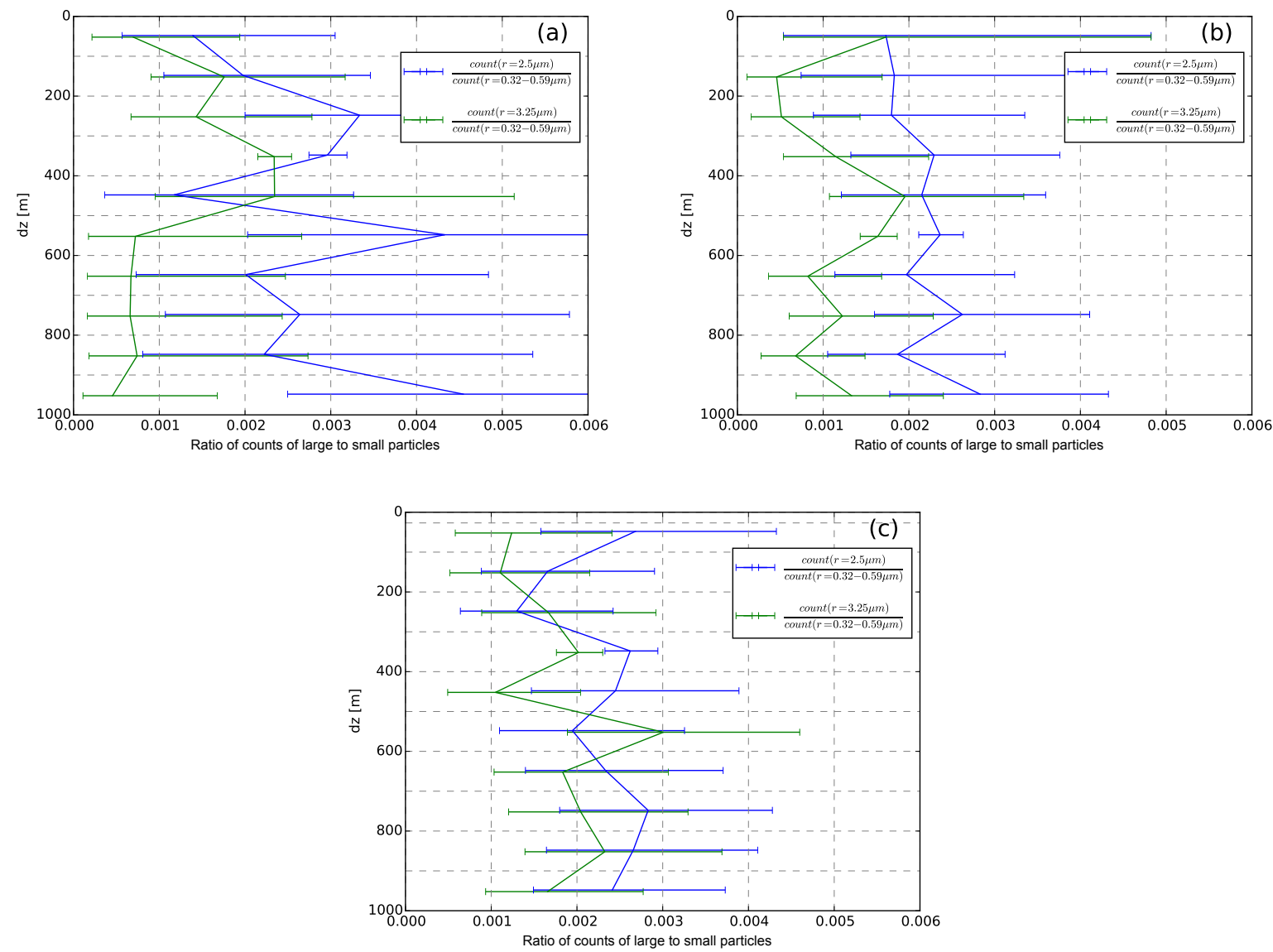

Figure 9. Ratios between counts in different size ranges measured by CAS-DPOL during aircraft ascent and descent (a) between 18:09 and 20:10 UTC on 22 June 2013, (b) between 15:14 and 16:42 UTC on 10 July 2013, and (c) between 12:45 and 13:50 UTC on 11 July 2013. The aircraft locations are illustrated in the Supplement S3. The vertical axis shows the distance from the SAL top. The data were grouped in $100 \mathrm{~m}$ wide vertical bins. The error bars are Poisson $95 \%$ confidence intervals.

\subsection{Optical particle counter measurements}

During SALTRACE, the Cloud and Aerosol Spectrometer with Depolarization Detection (CAS-DPOL manufactured by DMT, Boulder, CO, USA) was operated under a wing of the research aircraft Falcon of the Deutsches Zentrum für Luft- und Raumfahrt (DLR). The ambient air streams through this optical particle counter. It uses a laser as a light source operating at $\lambda=658 \mathrm{~nm}$ and measures the intensity of light scattered forward into $4-12^{\circ}$ by individual particles flying through its sampling area. Each particle is counted and from the measured intensity its size is inverted. The counts are collected in 30 size bins, covering a nominal radius range from 0.25 to $25 \mu \mathrm{m}$. These size bins and the size calibration used here were provided by the manufacturer of the instrument. The size-resolved in situ data from CAS-DPOL allow us to more directly test the maximum cutoff radius calculated in the case of $\mathrm{H} 1$.

For this test we use data from flights performed during daytime on the 22 June and 10 and 11 July 2013. The aircraft position at the time when the data used here were measured is illustrated in the Supplement S3. To extract the information about settling-induced separation of sizes, we use size bins for which we would expect no counts at low $\mathrm{d} z$ due to settling in the case of $\mathrm{H} 1$ and normalize them by counts measured with the same instrument in a size range that is almost not affected by settling (Fig. 1). The results are illustrated in Fig. 9. The blue lines show the counts in the nominal size bin $r=2.5 \mu \mathrm{m}$ (size bin no. 17), whereas the green lines show the counts in the nominal size bin $r=3.25 \mu \mathrm{m}$ (size bin no. 18), both normalized by the counts in the size bins from $r=0.32$ to $0.59 \mu \mathrm{m}$ (size bin nos. 2-9). Analysis of calibration measurements performed during SALTRACE suggests that the sizes presented here are underestimated because the instrument optics were polluted by dust particles, which reduced the amount of light reaching the detector.

The in situ data are available at $1 \mathrm{~s}$ resolution, which corresponds to about $8 \mathrm{~m}$ vertical resolution during ascent and descent of the investigated flights. Because of the low number of counts per second for coarse particles, we grouped the 
data in $100 \mathrm{~m}$ wide vertical bins. The vertical bins are described by their distance $\mathrm{d} z$ from the SAL top as determined from the CAS-DPOL data. The SAL top was at $3700 \mathrm{~m}$ a.s.l. both during ascent and descent on 22 June, at $5050 \mathrm{~m}$ a.s.l. during ascent and at $4900 \mathrm{~m}$ a.s.l. during descent on $10 \mathrm{July}$, and at $4630 \mathrm{~m}$ a.s.l. during ascent and at $4550 \mathrm{~m}$ a.s.l. during descent on 11 July 2013. Each $\mathrm{d} z$ bin covers about $25 \mathrm{~s}$ of data, except bins in which the ascent or descent was paused flying at constant altitude.

As illustrated in Fig. 1, in the case of our first hypothesis (H1), particles with $r \approx 2.5 \mu \mathrm{m}$ and larger are removed from $\mathrm{d} z<550 \mathrm{~m}$ after 5 days over the Atlantic. However, the curves in Fig. 9 show that such particles are also detected in the upper $100 \mathrm{~m}$ of the SAL near Barbados. This indicates $\mathrm{H} 1$ to be unrealistic even if intrinsic uncertainties of the size determination by CAS-DPOL on the order of $\pm 50 \%$ are assumed. A similar height dependence was also found during the PRIDE campaign, which was based in Puerto Rico (Reid et al., 2003). This suggests that some processes within the SAL keep large particles in the air longer than expected from gravitational settling.

\section{Comparison with average $\delta_{1}$ profiles from CALIOP}

After presenting SALTRACE case studies in the previous section, we now use averaged CALIOP $\delta_{1}$ profiles to get a more general view on the modification of the aerosols during the transport over the Atlantic and to test our hypotheses. We note that in reality the SAL transport is much more complex than our hypotheses assume and it varies from case to case. Nonetheless, we expect that averaged profiles of the intensive property $\delta_{1}$ contains evidence about whether the occurrence of vertical mixing within the SAL is typical or not. In the following, we first describe how we calculate the average $\delta_{1}$ from the CALIOP data, then compare our modeling results to the averaged profiles in the upper $1 \mathrm{~km}$ of the SAL, and finally discuss our findings.

\subsection{Averaging CALIOP data}

We restrict our analysis to $\delta_{1}$ at $532 \mathrm{~nm}$ because this parameter is relatively insensitive to errors encountered in the extinction-backscatter retrieval (Liu et al., 2013), which may result from uncertainties in the lidar ratio, for example (Wandinger et al., 2010; Amiridis et al., 2013). We again analyze the upper $1 \mathrm{~km}$ of the SAL, where potential settling and mixing effects should be observable with lidar (Fig. 7). We use CALIPSO level 2 aerosol profile products v3.01 (NASA, 2010) of backscatter coefficients $\beta$ and the perpendicular components of the backscatter coefficients $\beta_{\perp}$ at $\lambda=532 \mathrm{~nm}$ measured during summer 2007-2011, i.e., from June to August of each of the 5 years. We excluded profiles measured on 23 June and on 2 August 2009 because of unrealistic outliers found in the data from these days. Powell et al. (2009) describe how backscattering quantities are calculated from the CALIOP raw data. Vaughan et al. (2009) show the automated procedure for detecting aerosol and cloud layers using these backscattering quantities, and Liu et al. (2009) demonstrate how aerosols are discriminated from clouds. We restrict our evaluation to measurements in the region from 10 to $30^{\circ} \mathrm{N}$ and 0 to $75^{\circ} \mathrm{W}$. We group these measurements in three longitude ranges of $25^{\circ}$ width along the transport path from Africa to the western Atlantic. Only nighttime measurements are considered; all measurements were performed approximately $8 \mathrm{~h}$ after sunset.

The CALIOP measurements are performed with a vertical resolution of $30 \mathrm{~m}$ and a horizontal resolution of $330 \mathrm{~m}$. The backscatter coefficients $\beta$ and $\beta_{\perp}$ are provided in the level 2 data with a vertical resolution of $60 \mathrm{~m}$ (i.e., for bins of $60 \mathrm{~m}$ height) and a horizontal resolution of $5 \mathrm{~km}$, which reduces the noise compared to the measured resolution. As discussed by Vaughan et al. (2009), aerosol features are detected with $30 \mathrm{~m}$ vertical resolution using an iterative procedure starting with the horizontal resolution of $5 \mathrm{~km}$. Since the noise can be considerable at $5 \mathrm{~km}$ resolution, in particular if particle concentrations are low, the horizontal resolution is subsequently increased to 20 and $80 \mathrm{~km}$ to also detect weaker features. Depending on the results of the feature detection, the backscatter coefficients are horizontally averaged over 5 , 20 , or $80 \mathrm{~km}$, and the horizontal averaging range can depend on height. In the following we use only data horizontally averaged over $5 \mathrm{~km}$.

From the large set of aerosol profiles, profiles that fulfill the following criteria are selected for averaging:

- The uppermost aerosol-containing bin is between 3 and $8 \mathrm{~km}$ a.s.l.

- Both sub-bins ( $30 \mathrm{~m}$ height each) of the uppermost aerosol-containing bin are classified as aerosolcontaining.

- All 16 bins (i.e., up to $\approx 1 \mathrm{~km}$ ) below the uppermost aerosol-containing bin are also classified as aerosolcontaining.

- No cloud-containing bin is detected in or above the 17 uppermost aerosol-containing bins.

- Data is horizontally averaged over $5 \mathrm{~km}$ (not 20 or $80 \mathrm{~km}$ ) in each of the 17 uppermost aerosol-containing bins.

- Linear depolarization ratio $\delta_{1}$, averaged over the 17 uppermost aerosol-containing bins, is larger than 0.10 .

$\beta$ and $\beta_{\perp}$ of each of the 17 vertical bins is summed up over all selected profiles. From these sums, the average $\delta_{1}$ for each bin is calculated according to

$\delta_{1}=\frac{\sum \beta_{\perp}}{\sum \beta-\sum \beta_{\perp}}$. 


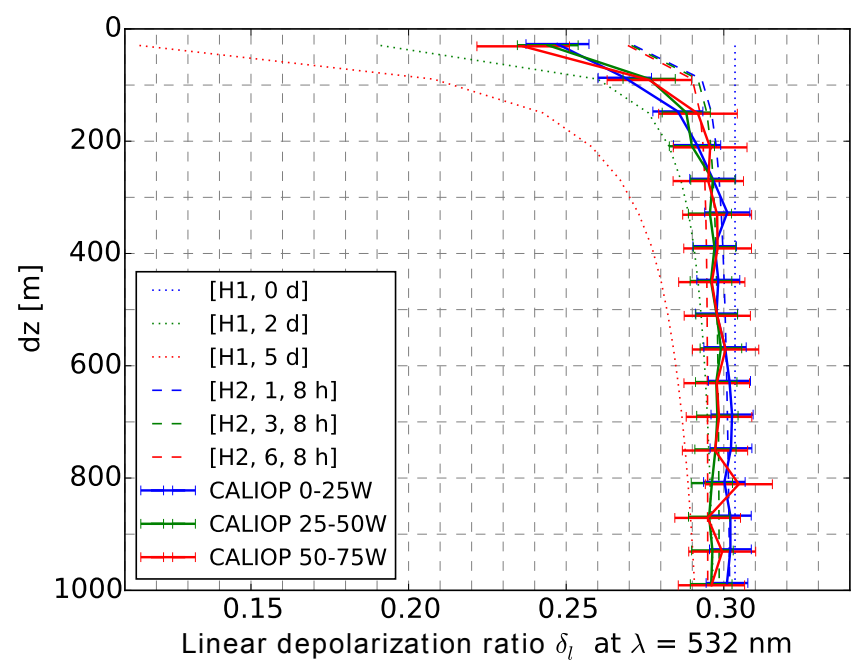

Figure 10. Linear depolarization ratio $\delta_{1}$ profiles at $\lambda=532 \mathrm{~nm}$ in the upper $1 \mathrm{~km}$ of the SAL. CALIOP profiles averaged over profiles from summer months 2007 to 2011 that fulfill conditions listed in the text are shown as solid blue, green, and red lines. The colors denote different longitude ranges. Error bars of the CALIOP profiles show the estimated statistical uncertainty $\Delta \delta_{1}$ of the average $\delta_{1}$. For comparison model results for both hypotheses are also shown as dotted (H1) and dashed (H2) lines.

The measurement uncertainties $\Delta \beta$ and $\Delta \beta_{\perp}$ provided in the CALIOP profile data are based on a simplified analysis assuming that all the uncertainties are random, uncorrelated, and produce no biases (Young, 2010). The magnitude of the uncertainties is mainly determined by the signal-to-noise ratio (Hunt et al., 2009). To calculate the estimated statistical uncertainty $\Delta \delta_{1}$ of the average $\delta_{1}$ value for each bin (Eq. 9), we sum up the squares of the measurement uncertainties of each profile and use

$$
\Delta \delta_{1}=\frac{\sqrt{\left(\sum \beta\right)^{2} \cdot \sum\left(\Delta \beta_{\perp}\right)^{2}+\left(\sum \beta_{\perp}\right)^{2} \cdot \sum(\Delta \beta)^{2}}}{\left(\sum \beta-\sum \beta_{\perp}\right)^{2}} .
$$

As we average over a large number of profiles, the uncertainties of the averaged profiles are reduced considerably compared to the uncertainties of single profiles.

\subsection{Comparison with averaged profiles}

Figure 10 shows the averaged $\delta_{1}$ profiles calculated from the CALIOP profile data considering all profiles that fulfilled the abovementioned criteria. The averaged data of the uppermost bin are plotted at $\mathrm{d} z \approx 30 \mathrm{~m}$, the subsequent bin at $\mathrm{d} z \approx 90 \mathrm{~m}$, etc. While the solid blue line shows the average $\delta_{1}$ close to the aerosol source region, the distance from the source region increases with the green line (central Atlantic) and red line (western Atlantic). A map illustrating these regions is provided in the Supplement S4. Averages were taken over 9061, 9114, and 3846 individual profiles in the three respec- tive regions along the SAL transport path. Considering the statistical uncertainty of the average, the average $\delta_{1}$ does not vary along the SAL transport path and is height-independent with values close to 0.30 for $\mathrm{d} z>250 \mathrm{~m}$. $\delta_{1}$ decreases towards the SAL top to values of about $0.23-0.25$ in the uppermost bin.

Comparing the measured with the modeled profiles, it becomes clear that the strong decrease of $\delta_{1}$ in the upper $100 \mathrm{~m}$ of the SAL, as modeled for long-range transport without vertical mixing ( $\mathrm{H} 1$, dotted red line), is not found in the averaged CALIOP data over the western Atlantic (solid red line). This indicates that our first hypothesis (H1) is unrealistic. A further result that renders $\mathrm{H} 1$ unlikely is the fact that the average $\delta_{1}$ profile from CALIOP is not modified during transport, while one would expect significant changes of the $\delta_{1}$ profile during transport if $\mathrm{H} 1$ is assumed (compare the dotted lines of different colors).

The dashed lines in Fig. 10 show the $\delta_{1}$ profile when daytime convective vertical mixing is assumed (H2). These modeled $\delta_{1}$ profiles are relatively height-independent, except in the upper $100 \mathrm{~m}$ of the SAL. Figure 10 shows that considering vertical mixing (using $\mathrm{H} 2$ instead of $\mathrm{H} 1$ ) considerably reduces the deviation of the model from the measurements after long-range transport. The measured invariability of the average $\delta_{1}$ profile between the different regions is also much better captured if $\mathrm{H} 2$ is assumed. Our model for $\mathrm{H} 2$ predicts a reduction of $\delta_{1}$ by about 0.007 at $\mathrm{d} z=1 \mathrm{~km}$ after about 5 days (see dashed lines). This reduction is not seen in the CALIOP profiles, possibly because it is within the range of the statistical uncertainty of the averaged $\delta_{1}$ profiles from CALIOP.

\subsection{Discussion of comparison with averaged profiles}

Our model assuming daytime vertical mixing (H2) explains the averaged CALIOP data and their invariability between the regions for the most part. However, deviations of the $\delta_{1}$ profile between this model and the averaged CALIOP data occur in the upper 2-3 bins (compare dashed to solid lines in Fig. 10). The measurements indicate on average a stronger removal of large particles in the upper $100 \mathrm{~m}$ of the SAL over Africa and over the Atlantic than $\mathrm{H} 2$ suggests. We again emphasize that we average over a large number of different cases. The $\delta_{1}$ profiles may vary from case to case, which is hard to quantify from the CALIOP data however because of large statistical uncertainties of single profiles.

One source of deviation could be our settling and vertical mixing model in $\mathrm{H} 2$. We assume perfect mixing of particles over the complete SAL when convection occurs and we assume a sharp boundary between the SAL and the layer above. However, it might be plausible that some mixing occurs between the SAL and the layer above on the order of 10 to $100 \mathrm{~m}$. Thus, some Saharan aerosol near the upper boundary of the SAL might become decoupled from the mixing within the SAL, allowing a stronger removal of large particles than $\mathrm{H} 2$ predicts. However, one fact that contradicts these con- 
siderations is that the measured $\delta_{1}$ profile seems to be independent of region, while one would expect that such effects become larger with distance from the source regions.

Another source of uncertainty is related to our aerosol model. Natural desert aerosol has very complex microphysical properties (e.g., Kandler et al., 2011), and as a consequence, our model of the Saharan aerosol mixtures contains several assumptions and the calculated optical properties are connected with uncertainties. Though we argue that our model mixture represents lidar-relevant optical properties of Saharan aerosols well (Gasteiger et al., 2011), we can not exclude that the deviations of the modeled $\delta_{1}$ profiles $(\mathrm{H} 2)$ from the averaged measurements in the upper 2-3 bins are related to assumptions in our aerosol mixture and the optical modeling approach.

A further aspect that needs to be kept in mind is that multiple scattering could affect the CALIOP measurements (Wandinger et al., 2010). In the case of our SAL top study, the multiple scattering effect would increase with increasing $\mathrm{d} z$ since the lidar pulse penetrates the SAL from its top. It is well-known that with an increasing amount of particles the multiple scattering effect increases (e.g., Bissonnette et al., 1995). Using the CALIOP profile data, we do not find a significant dependence of the $\delta_{1}$ profiles on the absolute values of $\beta$ (not shown), indicating that multiple scattering does not significantly affect the averaged $\delta_{1}$ profiles.

To investigate the CALIOP profiles in more detail, an analysis is provided in the Supplement S4, also considering 20 and $80 \mathrm{~km}$ horizontal averages, year-by-year variability, subbin classification, cloud-aerosol discrimination, and sensitivity to the $\delta_{1}$ threshold. The sensitivity of the averaged $\delta_{1}$ profile to these parameters was found to be low. As a consequence, it seems likely that the simplifications in $\mathrm{H} 2$ (including the optical model) are the reason for the remaining deviations near the SAL top. The average $\beta$ profile (see Supplement S4), as well as the variability of the backscatter coefficient $\beta$ from case to case (not shown), can also not be explained using $\mathrm{H} 2$, showing the need to consider in future research further aspects for precise SAL transport modeling.

\section{Summary and conclusions}

Transport of aerosol in the Saharan Air Layer (SAL) over the Atlantic is relevant for weather and climate but important processes within the SAL still are not well understood. To gain insights into relevant processes, we developed a model that describes the modification of the vertical aerosol distribution in the upper $1 \mathrm{~km}$ of the SAL during transport based on the physical processes of gravitational settling and vertical mixing. From the vertical aerosol distributions, lidar profiles are calculated using explicit optical modeling. Sensitivity studies revealed (a) that generally the particle linear depolarization ratio decreases towards the SAL top for all considered model shapes and (b) that the size dependence of the settling velocity is significantly more important for the linear depolarization ratio profile than the shape dependence of the settling velocity.

The model results were compared to lidar and in situ measurements and two hypotheses about the occurrence of vertical mixing within the SAL were tested (H1 without mixing, $\mathrm{H} 2$ with mixing during the day). Comparisons with groundbased depolarization lidar measurements in Barbados, performed in the framework of the SALTRACE campaign, revealed that the measurement uncertainties are in the same order as the differences between both hypotheses. Vertically resolved in situ measurements of the size distribution during SALTRACE found large particles in the upper part of the SAL that are not consistent with $\mathrm{H} 1$, indicating that vertical mixing occurs in the SAL over the Atlantic. These findings are supported by results from an analysis using nighttime data from CALIOP. The CALIOP data show that the average linear depolarization ratio profile in the upper $1 \mathrm{~km}$ of the SAL does not change along its transport path over the Atlantic, which disproves H1. These findings are consistent with results from other studies, which found that long-range transported Saharan aerosol contains unexpectedly large particles or that the aerosol properties do not change significantly during long-range transport, e.g., Reid et al. (2003); Maring et al. (2003); Weinzierl et al. (2011, 2016); Mahowald et al. (2014); Denjean et al. (2016a, b); van der Does et al. (2016).

We could show that vertical mixing occurs within the $\mathrm{SAL}$, and our model assuming daytime vertical mixing (H2), which is driven by the idea that the Saharan aerosol absorbs sunlight triggering convection, explains most data quite well. However, there are limitations of this idealized model. For example, profiles of extensive properties like the backscatter coefficient can often not be explained with $\mathrm{H} 2$, and remaining deviations from the averaged CALIOP depolarization data are still unexplained. We did not consider the possibility of weak vertical mixing, or size-selective particle removal at the lower boundary of the SAL during vertical mixing, or effects due to electrical fields in the SAL. Radiative effects in the thermal infrared might be an important aspect for understanding the vertical mixing in the SAL, as discussed by Carlson and Prospero (1972). The development of turbulence due to vertical wind shear, more realistic air layer dynamics, and feedbacks of radiative effects with the dynamics (Chen et al., 2010) are further possible aspects to be considered for a precise understanding of the processes within the SAL, their variability, and their effect on size distributions and lifetime of super-micron particles.

\section{Data availability}

The modeled and measured profile data are available upon request to Josef Gasteiger (josef.gasteiger@univie.ac.at). The 
CALIOP data were obtained via https://eosweb.larc.nasa. gov/project/calipso/cal_lid_12_05kmapro-prov-v3-01_table.

\section{The Supplement related to this article is available online at doi:10.5194/acp-17-297-2017-supplement.}

Acknowledgements. The research leading to these results received funding from LMU Munich's Institutional Strategy LMUexcellent within the framework of the German Excellence Initiative and from the European Research Council under the European Community's Horizon 2020 research and innovation framework program, ERC grant agreement no. 640458 - A-LIFE. Silke Groß acknowledges funding by a DLR VO-R young investigator group. The SALTRACE campaign was mainly funded by the Helmholtz Association, DLR, LMU, and TROPOS. The Caribbean Institute for Meteorology and Hydrology in Bridgetown, Barbados, kindly provided the infrastructure to perform the SALTRACE lidar measurements. The CALIOP data were obtained from the NASA Langley Research Center Atmospheric Science Data Center. We are grateful to Volker Freudenthaler for fruitful discussions on our model and the lidar data. We thank the reviewers for their suggestions that helped us to substantially improve our paper.

Edited by: C. Hoose

Reviewed by: two anonymous referees

\section{References}

Althausen, D., Müller, D., Ansmann, A., Wandinger, U., Hube, H., Clauder, E., and Zörner, S.: Scanning 6-Wavelength 11-Channel Aerosol Lidar, J. Atmos. Ocean. Technol., 17, 1469-1482, doi:10.1175/1520-0426(2000)017<1469:SWCAL>2.0.CO;2, 2000

Amiridis, V., Wandinger, U., Marinou, E., Giannakaki, E., Tsekeri, A., Basart, S., Kazadzis, S., Gkikas, A., Taylor, M., Baldasano, J., and Ansmann, A.: Optimizing CALIPSO Saharan dust retrievals, Atmos. Chem. Phys., 13, 12089-12106, doi:10.5194/acp-1312089-2013, 2013.

Anderson, G. P., Clough, S. A., Kneizys, F. X., Chetwynd, J. H., and Shettle, E. P.: AFGL atmospheric constituent profiles $(0$ $120 \mathrm{~km})$, Tech. rep., AFGL-TR-86-0110, Environemental Research papers No. 954, 1986.

Ansmann, A., Petzold, A., Kandler, K., Tegen, I., Wendisch, M., Müller, D., Weinzierl, B., Müller, T., and Heintzenberg, J.: Saharan Mineral Dust Experiments SAMUM-1 and SAMUM-2: What have we learned?, Tellus B, 63, 403-429, doi:10.1111/j.1600-0889.2011.00555.x, 2011.

Ben-Ami, Y., Koren, I., and Altaratz, O.: Patterns of North African dust transport over the Atlantic: winter vs. summer, based on CALIPSO first year data, Atmos. Chem. Phys., 9, 7867-7875, doi:10.5194/acp-9-7867-2009, 2009.

Bissonnette, L. R., Bruscaglioni, P., Ismaelli, A., Zaccanti, G., Cohen, A., Benayahu, Y., Kleiman, M., Egert, S., Flesia, C., Schwendimann, P., Starkov, A. V., Noormohammadian, M., Oppel, U. G., Winker, D. M., Zege, E. P., Katsev, I. L., and Polonsky,
I. N.: LIDAR multiple scattering from clouds, Appl. Phys. B, 60, 355-362, doi:10.1007/BF01082271, 1995.

Carlson, T. N. and Prospero, J. M.: The large-scale movement of Saharan air outbreaks over the northern equatorial Atlantic, J. Appl. Meteor., 11, 283-297, doi:10.1175/15200450(1972)011<0283:TLSMOS>2.0.CO;2, 1972.

Chen, S.-H., Wang, S.-H., and Waylonis, M.: Modification of Saharan air layer and environmental shear over the eastern Atlantic Ocean by dust-radiation effects, J. Geophys. Res.-Atmos., 115, D21202, doi:10.1029/2010JD014158, 2010.

Clift, R., Grace, J. R., and Weber, M. E.: Bubbles, Drops, and Particles, Academic Press, 380 pp., 1978.

Cuesta, J., Marsham, J. H., Parker, D. J., and Flamant, C.: Dynamical mechanisms controlling the vertical redistribution of dust and the thermodynamic structure of the West Saharan atmospheric boundary layer during summer, Atmos. Sci. Lett., 10, 34-42, doi:10.1002/asl.207, 2009.

Denjean, C., Cassola, F., Mazzino, A., Triquet, S., Chevaillier, S., Grand, N., Bourrianne, T., Momboisse, G., Sellegri, K., Schwarzenbock, A., Freney, E., Mallet, M., and Formenti, P.: Size distribution and optical properties of mineral dust aerosols transported in the western Mediterranean, Atmos. Chem. Phys., 16, 1081-1104, doi:10.5194/acp-16-1081-2016, 2016 a.

Denjean, C., Formenti, P., Desboeufs, K., Chevaillier, S., Triquet, S., Maillé, M., Cazaunau, M., Laurent, B., Mayol-Bracero, O. L., Vallejo, P., Quiñones, M., Gutierrez-Molina, I. E., Cassola, F., Prati, P., Andrews, E., and Ogren, J.: Size distribution and optical properties of African mineral dust after intercontinental transport, J. Geophys. Res.-Atmos., 121, 7117-7138, doi:10.1002/2016JD024783, 2016 b.

Esselborn, M., Wirth, M., Fix, A., Weinzierl, B., Rasp, K., Tesche, M., and Petzold, A.: Spatial distribution and optical properties of Saharan dust observed by airborne high spectral resolution lidar during SAMUM 2006, Tellus B, 61, 131-143, doi:10.1111/j.1600-0889.2008.00394.x, 2009.

Freudenthaler, V., Seefeldner, M., Groß, S., and Wandinger, U.: Accuracy of linear depolarization ratios in clean air ranges measured with POLIS-6 at 355 and $532 \mathrm{~nm}$, EPJ Web of Conferences, 119, 25013, doi:10.1051/epjconf/201611925013, 2016.

Gasteiger, J., Wiegner, M., Groß, S., Freudenthaler, V., Toledano, C., Tesche, M., and Kandler, K.: Modeling lidar-relevant optical properties of complex mineral dust aerosols, Tellus B, 63, 725741, doi:10.1111/j.1600-0889.2011.00559.x, 2011.

Ginoux, P.: Effects of nonsphericity on mineral dust modeling, J. Geophys. Res.-Atmos., 108, 4052, doi:10.1029/2002JD002516, 2003.

Groß, S., Freudenthaler, V., Schepanski, K., Toledano, C., Schäfler, A., Ansmann, A., and Weinzierl, B.: Optical properties of longrange transported Saharan dust over Barbados as measured by dual-wavelength depolarization Raman lidar measurements, Atmos. Chem. Phys., 15, 11067-11080, doi:10.5194/acp-1511067-2015, 2015.

Haarig, M., Althausen, D., Ansmann, A., Klepel, A., Baars, H., Engelmann, R., Groß, S., and Freudenthaler, V.: Measurement of the Linear Depolarization Ratio of Aged Dust at Three Wavelengths (355, 532 and $1064 \mathrm{~nm}$ ) Simultaneously over Barbados, EPJ Web of Conferences, 119, 18009, doi:10.1051/epjconf/201611918009, 2016. 
Heintzenberg, J.: The SAMUM-1 experiment over Southern Morocco: overview and introduction, Tellus B, 61, 2-11, doi:10.1111/j.1600-0889.2008.00403.x, 2009.

Hess, M., Koepke, P., and Schult, I.: Optical Properties of Aerosols and Clouds: The Software Package OPAC, B. Am. Meteor. Soc., 79, 831-844, doi:10.1175/15200477(1998)079<0831:OPOAAC>2.0.CO;2, 1998.

Hinds, W. C.: Aerosol technology: properties, behavior, and measurement of airborne particles, John Wiley \& Sons, 504 pp., 1999.

Hunt, W. H., Winker, D. M., Vaughan, M. A., Powell, K. A., Lucker, P. L., and Weimer, C.: CALIPSO Lidar Description and Performance Assessment, J. Atmos. Ocean. Technol., 26, 1214-1228, doi:10.1175/2009JTECHA1223.1, 2009.

Järvinen, E., Kemppinen, O., Nousiainen, T., Kociok, T., Möhler, O., Leisner, T., and Schnaiter, M.: Laboratory investigations of mineral dust near-backscattering depolarization ratios, J. Quant. Spectrosc. Rad. Trans., 178, 192-208, doi:10.1016/j.jqsrt.2016.02.003, 2016.

Kaaden, N., Massling, A., Schladitz, A., Müller, T., Kandler, K., Schütz, L., Weinzierl, B., Petzold, A., Tesche, M., Leinert, S., Deutscher, C., Ebert, M., Weinbruch, S., and Wiedensohler, A.: State of mixing, shape factor, number size distribution, and hygroscopic growth of the Saharan anthropogenic and mineral dust aerosol at Tinfou, Morocco, Tellus B, 61, 51-63, doi:10.1111/j.1600-0889.2008.00388.x, 2009.

Kandler, K., Lieke, K., Benker, N., Emmel, C., Küpper, M., MüllerEbert, D., Scheuvens, D., Schladitz, A., Schütz, L., and Weinbruch, S.: Electron microscopy of particles collected at Praia, Cape Verde, during the Saharan Mineral dust experiment: particle chemistry, shape, mixing state and complex refractive index, Tellus B, 63, 475-496, doi:10.1111/j.1600-0889.2011.00550.x, 2011.

Knippertz, P., Ansmann, A., Althausen, D., Müller, D., Tesche, M., Bierwirth, E., Dinter, T., Müller, T., Von Hoyningen-Huene, W., Schepanski, K., Wendisch, M., Heinold, B., Kandler, K., Petzold, A., Schütz, L., and Tegen, I.: Dust mobilization and transport in the northern Sahara during SAMUM 2006 - a meteorological overview, Tellus B, 61, 12-31, doi:10.1111/j.16000889.2008.00380.x, 2009.

Koepke, P., Gasteiger, J., and Hess, M.: Technical Note: Optical properties of desert aerosol with non-spherical mineral particles: data incorporated to OPAC, Atmos. Chem. Phys., 15, 59475956, doi:10.5194/acp-15-5947-2015, 2015.

Liu, Z., Omar, A., Vaughan, M., Hair, J., Kittaka, C., Hu, Y., Powell, K., Trepte, C., Winker, D., Hostetler, C., Ferrare, R., and Pierce, R.: CALIPSO lidar observations of the optical properties of Saharan dust: A case study of long-range transport, J. Geophys. Res., 113, D07207, doi:10.1029/2007JD008878, 2008.

Liu, Z., Vaughan, M., Winker, D., Kittaka, C., Getzewich, B., Kuehn, R., Omar, A., Powell, K., Trepte, C., and Hostetler, C.: The CALIPSO Lidar Cloud and Aerosol Discrimination: Version 2 Algorithm and Initial Assessment of Performance, J. Atmos. Ocean. Technol., 26, 1198-1213, doi:10.1175/2009JTECHA1229.1, 2009.

Liu, Z., Fairlie, T. D., Uno, I., Huang, J., Wu, D., Omar, A., Kar, J., Vaughan, M., Rogers, R., Winker, D., Trepte, C., Hu, Y., Sun, W., Lin, B., and Cheng, A.: Transpacific transport and evolution of the optical properties of Asian dust, J. Quant. Spectrosc. Rad. Trans., 116, 24-33, doi:10.1016/j.jqsrt.2012.11.011, 2013.

Loth, E.: Drag of non-spherical solid particles of regular and irregular shape, Powder Technol., 182, 342-353, doi:10.1016/j.powtec.2007.06.001, 2008.

Mahowald, N., Albani, S., Kok, J. F., Engelstaeder, S., Scanza, R., Ward, D. S., and Flanner, M. G.: The size distribution of desert dust aerosols and its impact on the Earth system, Aeolian Res., 15, 53-71, doi:10.1016/j.aeolia.2013.09.002, 2014.

Maring, H., Savoie, D. L., Izaguirre, M. A., Custals, L., and Reid, J. S.: Mineral dust aerosol size distribution change during atmospheric transport, J. Geophys. Res.-Atmos., 108, 8592, doi:10.1029/2002JD002536, 2003.

Mattis, I., Ansmann, A., Müller, D., Wandinger, U., and Althausen, D.: Dual-wavelength Raman lidar observations of the extinctionto-backscatter ratio of Saharan dust, Geophys. Res. Lett., 29, 201-20-4, doi:10.1029/2002GL014721, 2002.

NASA: CALIPSO Lidar Level 2 Aerosol Profile Products Version 3.01, doi:10.5067/CALIOP/CALIPSO/CAL_LID_L2_05kmAProProv-V3-01_L2-003.01, 2010.

Otto, S., Bierwirth, E., Weinzierl, B., Kandler, K., Esselborn, M., Tesche, M., Schladitz, A., Wendisch, M., and Trautmann, T.: Solar radiative effects of a Saharan dust plume observed during SAMUM assuming spheroidal model particles, Tellus B, 61, 270296, doi:10.1111/j.1600-0889.2008.00389.x, 2009.

Papayannis, A., Amiridis, V., Mona, L., Tsaknakis, G., Balis, D., Bösenberg, J., Chaikovski, A., de Tomasi, F., Grigorov, I., Mattis, I., Mitev, V., Müller, D., Nickovic, S., Pérez, C., Pietruczuk, A., Pisani, G., Ravetta, F., Rizi, V., Sicard, M., Trickl, T., Wiegner, M., Gerding, M., Mamouri, R. E., D’Amico, G., and Pappalardo, G.: Systematic lidar observations of Saharan dust over Europe in the frame of EARLINET (2000-2002), J. Geophys. Res., 113, D10204, doi:10.1029/2007JD009028, 2008.

Pappalardo, G., Amodeo, A., Apituley, A., Comeron, A., Freudenthaler, V., Linné, H., Ansmann, A., Bösenberg, J., D’Amico, G., Mattis, I., Mona, L., Wandinger, U., Amiridis, V., AladosArboledas, L., Nicolae, D., and Wiegner, M.: EARLINET: towards an advanced sustainable European aerosol lidar network, Atmos. Meas. Tech., 7, 2389-2409, doi:10.5194/amt-7-23892014, 2014.

Powell, K. A., Hostetler, C. A., Vaughan, M. A., Lee, K.-P., Trepte, C. R., Rogers, R. R., Winker, D. M., Liu, Z., Kuehn, R. E., Hunt, W. H., and Young, S. A.: CALIPSO Lidar Calibration Algorithms. Part I: Nighttime 532-nm Parallel Channel and 532-nm Perpendicular Channel, J. Atmos. Ocean. Technol., 26, 20152033, doi:10.1175/2009JTECHA1242.1, 2009.

Prospero, J. M. and Carlson, T. N.: Vertical and areal distribution of Saharan dust over the western equatorial North Atlantic Ocean, J. Geophys. Res., 77, 5255-5265, doi:10.1029/JC077i027p05255, 1972.

Reid, J. S., Kinney, J. E., Westphal, D. L., Holben, B. N., Welton, E. J., Tsay, S., Eleuterio, D. P., Campbell, J. R., Christopher, S. A., Colarco, P. R., Jonsson, H. H., Livingston, J. M., Maring, H. B., Meier, M. L., Pilewskie, P., Prospero, J. M., Reid, E. A., Remer, L. A., Russell, P. B., Savoie, D. L., Smirnov, A., and Tanré, D.: Analysis of measurements of Saharan dust by airborne and ground-based remote sensing methods during 
the Puerto Rico Dust Experiment (PRIDE), J. Geophys. Res.Atmos., 108, 8586, doi:10.1029/2002JD002493, 2003.

Ryder, C. L., Highwood, E. J., Rosenberg, P. D., Trembath, J., Brooke, J. K., Bart, M., Dean, A., Crosier, J., Dorsey, J., Brindley, H., Banks, J., Marsham, J. H., McQuaid, J. B., Sodemann, H., and Washington, R.: Optical properties of Saharan dust aerosol and contribution from the coarse mode as measured during the Fennec 2011 aircraft campaign, Atmos. Chem. Phys., 13, 303325, doi:10.5194/acp-13-303-2013, 2013.

Sakai, T., Nagai, T., Zaizen, Y., and Mano, Y.: Backscattering linear depolarization ratio measurements of mineral, sea-salt, and ammonium sulfate particles simulated in a laboratory chamber, Appl. Opt., 49, 4441-4449, doi:10.1364/AO.49.004441, 2010.

Sassen, K.: The Polarization Lidar Technique for Cloud Research: A Review and Current Assessment, B. Am. Meteor. Soc., 72, 1848-1866, doi:10.1175/15200477(1991)072<1848:TPLTFC>2.0.CO;2, 1991.

Schütz, L.: Long range transport of desert dust with special emphasis on the Sahara, Ann. NY Acad. Sci., 338, 515-532, doi:10.1111/j.1749-6632.1980.tb17144.x, 1980.

Stein, A. F., Draxler, R. R., Rolph, G. D., Stunder, B. J. B., Cohen, M. D., and Ngan, F.: NOAA's HYSPLIT Atmospheric Transport and Dispersion Modeling System, B. Am. Meteor. Soc., 96, 2059-2077, doi:10.1175/BAMS-D-14-00110.1, 2015.

Tsamalis, C., Chédin, A., Pelon, J., and Capelle, V.: The seasonal vertical distribution of the Saharan Air Layer and its modulation by the wind, Atmos. Chem. Phys., 13, 11235-11257, doi:10.5194/acp-13-11235-2013, 2013.

Ulanowski, Z., Bailey, J., Lucas, P. W., Hough, J. H., and Hirst, E.: Alignment of atmospheric mineral dust due to electric field, Atmos. Chem. Phys., 7, 6161-6173, doi:10.5194/acp-7-6161-2007, 2007.

van der Does, M., Korte, L. F., Munday, C. I., Brummer, G.J. A., and Stuut, J.-B. W.: Particle size traces modern Saharan dust transport and deposition across the equatorial North Atlantic, Atmos. Chem. Phys., 16, 13697-13710, doi:10.5194/acp16-13697-2016, 2016.

Vaughan, M. A., Powell, K. A., Kuehn, R. E., Young, S. A., Winker, D. M., Hostetler, C. A., Hunt, W. H., Liu, Z., McGill, M. J., and Getzewich, B. J.: Fully Automated Detection of Cloud and Aerosol Layers in the CALIPSO Lidar Measurements, J. Atmos. Ocean. Technol., 26, 2034-2050, doi:10.1175/2009JTECHA1228.1, 2009.

Wandinger, U., Tesche, M., Seifert, P., Ansmann, A., Müller, D., and Althausen, D.: Size matters: Influence of multiple scattering on CALIPSO light-extinction profiling in desert dust, Geophys. Res. Lett., 37, L10801, doi:10.1029/2010GL042815, 2010.
Weinzierl, B., Petzold, A., Esselborn, M., Wirth, M., Rasp, K., Kandler, K., Schütz, L., Koepke, P., and Fiebig, M.: Airborne measurements of dust layer properties, particle size distribution and mixing state of Saharan dust during SAMUM 2006, Tellus B, 61, 96-117, doi:10.1111/j.1600-0889.2008.00392.x, 2009.

Weinzierl, B., Sauer, D., Esselborn, M., Petzold, A., Veira, A., Rose, M., Mund, S., Wirth, M., Ansmann, A., Tesche, M., Groß, S., and Freudenthaler, V.: Microphysical and optical properties of dust and tropical biomass burning aerosol layers in the Cape Verde region - An overview of the airborne in situ and lidar measurements during SAMUM-2, Tellus B, 63, 589-618, doi:10.1111/j.16000889.2011.00566.x, 2011.

Weinzierl, B., Ansmann, A., Prospero, J. M., Althausen, D., Benker, N., Chouza, F., Dollner, M., Farrell, D., Fomba, W. K., Freudenthaler, V., Gasteiger, J., Groß, S., Haarig, M., Heinold, B., Kandler, K., Kristensen, T. B., Mayol-Bracero, O. L., Müller, T., Reitebuch, O., Sauer, D., Schäfler, A., Schepanski, K., Spanu, A., Tegen, I., Toledano, C., and Walser, A.: The Saharan Aerosol Long-range Transport and Aerosol-Cloud-Interaction Experiment (SALTRACE): overview and selected highlights, B. Am Meteor. Soc., doi:10.1175/BAMS-D-15-00142.1, 2016.

Wiegner, M., Groß, S., Freudenthaler, V., Schnell, F., and Gasteiger, J.: The May/June 2008 Saharan dust event over Munich: Intensive aerosol parameters from lidar measurements, J. Geophys. Res., 116, D23213, doi:10.1029/2011JD016619, 2011.

Winker, D. M., Vaughan, M. A., Omar, A., Hu, Y., Powell, K. A., Liu, Z., Hunt, W. H., and Young, S. A.: Overview of the CALIPSO Mission and CALIOP Data Processing Algorithms, J. Atmos. Ocean. Technol., 26, 2310-2323, doi:10.1175/2009JTECHA1281.1, 2009.

Yang, W., Marshak, A., Kostinski, A. B., and Várnai, T.: Shape-induced gravitational sorting of Saharan dust during transatlantic voyage: Evidence from CALIOP lidar depolarization measurements, Geophys. Res. Lett., 40, 3281-3286, doi:10.1002/grl.50603, 2013.

Young, S. A.: Uncertainty Analysis for Particulate Backscatter, Extinction and Optical Depth Retrievals reported in the CALIPSO Level 2, Version 3 Data Release, https://eosweb.larc.nasa.gov/sites/default/files/project/calipso/ CALIOP_Version3_Extinction_Error_Analysis.pdf, (last access: 3 January 2017), 2010.

Yurkin, M. A. and Hoekstra, A. G.: The discrete-dipoleapproximation code ADDA: Capabilities and known limitations, J. Quant. Spectrosc. Rad. Trans., 112, 2234-2247, doi:10.1016/j.jqsrt.2011.01.031, 2011. 